\title{
Biomarker analysis to predict the pathological response to neoadjuvant chemotherapy in locally advanced gastric cancer: An exploratory biomarker study of COMPASS, a randomized phase II trial
}

\author{
Takashi Oshima1, Takaki Yoshikawa², Yohei Miyagi ${ }^{3}$, Satoshi Morita ${ }^{4}$, \\ Michio Yamamoto5, Kazuaki Tanabe ${ }^{6}$, Kazuhiro Nishikawa7, Yuichi Ito ${ }^{8}$, \\ Takanori Matsui ${ }^{9}$, Yutaka Kimura ${ }^{10}$, Tomoyuki Yokose ${ }^{13}$, Yukihiko Hiroshima ${ }^{3}$, \\ Toru Aoyama ${ }^{11}$, Tsutomu Hayashi ${ }^{2}$, Takashi Ogata ${ }^{1}$, Haruhiko Cho ${ }^{12}$, Yasushi Rino ${ }^{11}$, \\ Munetaka Masuda11, Akira Tsuburaya ${ }^{14}$ and Junichi Sakamoto ${ }^{15}$ \\ ${ }^{1}$ Department of Gastrointestinal Surgery, Kanagawa Cancer Center, Asahi-ku, Yokohama, Kanagawa 241-8515, Japan \\ ${ }^{2}$ Department of Gastric Surgery, National Cancer Hospital, Chuo-ku, Tokyo 104-0045, Japan \\ ${ }^{3}$ Kanagawa Cancer Center Research Institute, Asahi-ku, Yokohama, Kanagawa 241-8515, Japan \\ ${ }^{4}$ Department of Biomedical Statistics and Bioinformatics, Kyoto University Graduate School of Medicine, Sakyo-ku, Kyoto, \\ Kyoto 606-8507, Japan \\ ${ }^{5}$ Graduate School of Environmental and Life Science, Okayama University, Kita-ku, Okayama, Okayama 700-8530, Japan \\ ${ }^{6}$ Department of Gastroenterological and Transplant Surgery, Hiroshima University, Minami-ku, Hiroshima, Hiroshima 734- \\ 8551 , Japan \\ ${ }^{7}$ Department of Surgery, National Hospital Organization Osaka National Hospital, Chuo-ku, Osaka, Osaka, 540-0006, Japan \\ ${ }^{8}$ Department of Gastroenterological Surgery, Aichi Cancer Center Hospital, Chikusa-ku, Nagoya, Aichi 464-8681, Japan \\ 'Department of Surgery, Aichi Cancer Center, Aichi Hospital, Kakemachi, Okazaki, Aichi 444-0011, Japan \\ ${ }^{10}$ Department of Surgery, NTT West Japan Osaka Hospital, Tennouji-ku, Osaka, Osaka 543-0042, Japan \\ ${ }^{11}$ Department of Surgery, Yokohama City University, Kanazawa-ku, Yokohama, Kanagawa 236-0004, Japan \\ ${ }^{12}$ Department of Gastric Surgery, Tokyo Metropolitan Cancer and Infectious Diseases Center Komagome Hospital, Bunkyo- \\ ku, Tokyo 113-8677, Japan \\ ${ }^{13}$ Department of Pathology, Kanagawa Cancer Center, Asahi-ku, Yokohama, Kanagawa 241-8515, Japan \\ ${ }^{14}$ Department of Surgery, Ozawa Hospital, Odawara, Kanagawa 250-0012, Japan \\ ${ }^{15}$ Tokai Central Hospital, Kakamigahara, Gifu 504-8601, Japan
}

Correspondence to: Takaki Yoshikawa, email: tayoshik@ncc.go.jp

Keywords: gastric cancer; neoadjuvant chemotherapy; pathological response; predictive biomarkers; personalized therapy Received: November 24, $2018 \quad$ Accepted: June 05, 2020

Published: July 28, 2020

Copyright: Oshima et al. This is an open-access article distributed under the terms of the Creative Commons Attribution License 3.0 (CC BY 3.0), which permits unrestricted use, distribution, and reproduction in any medium, provided the original author and source are credited.

\section{ABSTRACT}

Background: The findings of COMPASS, a randomized phase II study, suggested that the regimens and courses of neoadjuvant chemotherapy (NAC) for locally advanced gastric cancer (GC) did not affect the pathological response. However, pathological complete response was achieved in $10 \%$ patients who received four courses of either S-1/cisplatin or paclitaxel/cisplatin. We hypothesized that if relevant biomarkers could be used to predict the suitable NAC regimen before treatment initiation, further improvements could be ensured in the outcomes of locally advanced GC.

Materials and Methods: mRNA extraction, real-time polymerase chain reaction, and immunohistochemical analyses were performed using endoscopic biopsy specimens of primary tumors, collected prior to NAC, to determine the clinically relevant biomarkers.

Results: TIMP1, DSG2, RRM1, MUC2, EGFR, ZDHHC14, and CLDN18.2 were identified as biomarker candidates, since their expression was significantly associated with the 


\begin{abstract}
pathological responses to each NAC regimen. Furthermore, TIMP1 and DSG2 were identified as predictive biomarkers of the pathological response to each NAC regimen. Conclusions: The effective prediction of the pathological response to NAC regimens in locally advanced GC using biomarkers identified from endoscopic biopsy specimens indicates the possibility of personalizing NAC based on biomarker analysis.
\end{abstract}

\section{INTRODUCTION}

Gastric cancer (GC) is a disease of global relevance. With an estimated 1 million new cases each year, it is the fifth most commonly diagnosed malignancy worldwide. In 2018, 784,000 people died worldwide, making it the third leading cause of cancer-related deaths [1]. Currently, standard treatments for locally advanced GC in Asia, Europe, and the United States include curative gastrectomy followed by adjuvant chemotherapy, surgery with pre- and postoperative chemotherapy, and surgery with postoperative chemoradiotherapy [2-6]. Recent phase III trials [2-4] revealed that adjuvant chemotherapy after curative gastrectomy improved the overall survival (OS) in patients with locally advanced GC. However, even after curative resection, the outcomes of adjuvant chemotherapy administered after gastrectomy are insubstantial $[7,8]$, and chemotherapy of greater intensity is necessary to further improve the survival rates.

Neoadjuvant chemotherapy (NAC) is considered effective for the treatment of stage III locally advanced GC. NAC is a form of multidisciplinary treatment in which chemotherapy is used initially to reduce the tumor size and eliminate micro-metastases, following which the remaining primary and metastatic lesions are excised. The advantages of neoadjuvant chemotherapy include a high rate of R0 resection, tumor regression, high compliance, and the avoidance of unnecessary surgery [9]. However, positive results are yet to be achieved in phase III studies on NAC conducted thus far. Although the results of twophase III randomized studies on NAC in locally advanced GC, JCOG0501 [10] and PRODIGY [11], were recently reported, similar to the results from previous trials, there were no significant differences in OS between patients who received and did not receive NAC.

A randomized phase II study (COMPASS) was conducted to determine the optimal regimen and the number of courses of NAC, and to compare the effectiveness of two or four courses of NAC with that of S-1/cisplatin (SC) or paclitaxel/cisplatin (PC) in 83 patients with locally advanced GC using a two-by-two factorial design. The results revealed that there was no significant difference between the pathological responses to $\mathrm{SC}$ and PC or those to two and four courses of NAC. However, it was noteworthy that pathological complete response was achieved in $10 \%$ of the patients who received four courses of either SC or PC [12]. This suggested that a significant pathological response might be achieved by administering an appropriate regimen of NAC for a certain time period; that is, if the pathological response to each NAC regimen can be predicted prior to the initiation of therapy and the personalization of NAC can be facilitated, the outcomes could be expected to improve. This study on COMPASS trial biomarkers investigated the relevant biomarkers that could predict the pathological response to each NAC regimen in locally advanced GC.

\section{RESULTS}

\section{Biomarker study cohort}

A CONSORT diagram is presented in Figure 1. Among the 83 patients enrolled in the COMPASS trial, 41 and 42 patients were assigned to receive $\mathrm{SC}$ and $\mathrm{PC}$, respectively (cohort 1). Seventy-nine GC tissue specimens that had been obtained endoscopically from each patient before NAC initiation were collected, and 46 samples were further used in the biomarker study (cohort 2). Although stage IV patients with peritoneal dissemination or non-local lymph nodes metastasis did not undergo resection in this study, four patients with no peritoneal metastasis and peritoneal lavage cytology positive (P0 CY1) underwent gastrectomy with D2 lymph node resection. These procedures are adopted from previous reports of positive outcomes in patients who underwent gastrectomy with D2 lymph node dissection followed by chemotherapy with S-1 for P0 CY1 GC [13], as well as on Japanese GC treatment guidelines (ver. 5). The outcomes in the patients with P0 CY1 included in this study were considerably encouraging. Therefore, in this study, the pathological response in primary tumors was evaluated using specimens obtained from patients, including those with P0 CY1.

The patient characteristics and pathological responses in the primary tumors were then compared between cohort 1 and 2 in the SC and PC arms. There was no different between the patient characteristics of cohorts 1 and 2 in the SC or PC arms, (Table 1). Furthermore, there was no significant difference in the patient characteristics between the cohorts in the SC or the PC arms (Table 2).

\section{Biomarker candidates at the mRNA level that predict the pathological response of locally advanced GC to each NAC regimen}

The following genes were denoted as biomarker candidates: metallopeptidase inhibitor 1 (TIMP1), desmoglein-2 (DSG2), ribonucleotide reductase catalytic 
subunit M1 (RRM1), mucin-2 (MUC2), epidermal growth factor receptor $(E G F R)$, DHHC-type palmitoyl transferase 14 (ZDHHC14), and claudin-18 isoform 2 (CLDN18.2); the expression profiles of these genes had a significant association with pathological responses to SC or PC.

When biomarker candidates at the mRNA level were divided into high and low expression biomarkers based on the cutoff values determined using statistical analysis methods, (as shown in materials and methods), the high expression of TIMP1, DSG2, RRM1, and MUC2, and the low expression of EGFR, ZDHHC14, and CLDN18.2 appeared to be associated with a better pathological response to SC. In addition, the high expression of $E G F R$, ZDHHC14, and CLDN18.2 and the low expression of TIMP1, DSG2, RRM1, and MUC2 were associated with a better pathological response to PC (Table 3, Supplementary Table 1).

\section{Relationship between the expression profile each biomarker candidate and the clinicopathological factors}

There was no significant difference between the mRNA expression levels of the seven biomarker candidates (EGFR, ZDHHC14, CLDN18.2, TIMP1, $D S G 2, M U C 2$, and $R R M 1)$ and the clinicopathological factors $(n=46)$ (Supplementary Table 2$)$.

As a reference, the relationship between the expression levels of seven biomarker candidates and the clinicopathological factors in different cohort of locally advanced GC $(n=253)$ was examined, a significant association existed between the expression levels of $D S G$ and histological type and tumor depth, of CLDN18.2 and the incidence of venous invasion, of $E G F R$ and that of lymph node metastasis and venous invasion, of $M U C 2$ and that of venous invasion (Supplementary Table 3).

\section{Relationship between protein and gene expression determined by immunohistochemical and mRNA expression analyses, respectively, of the same specimens}

Representative images of high and low immunostaining for determining the levels of EGFR, ZDHHC14, CLDN18.2, TIMP1, DSG2, MUC2, and RRM1 are shown in Figure 2.

The expression of proteins encoded by the biomarker candidates was evaluated at the mRNA level in

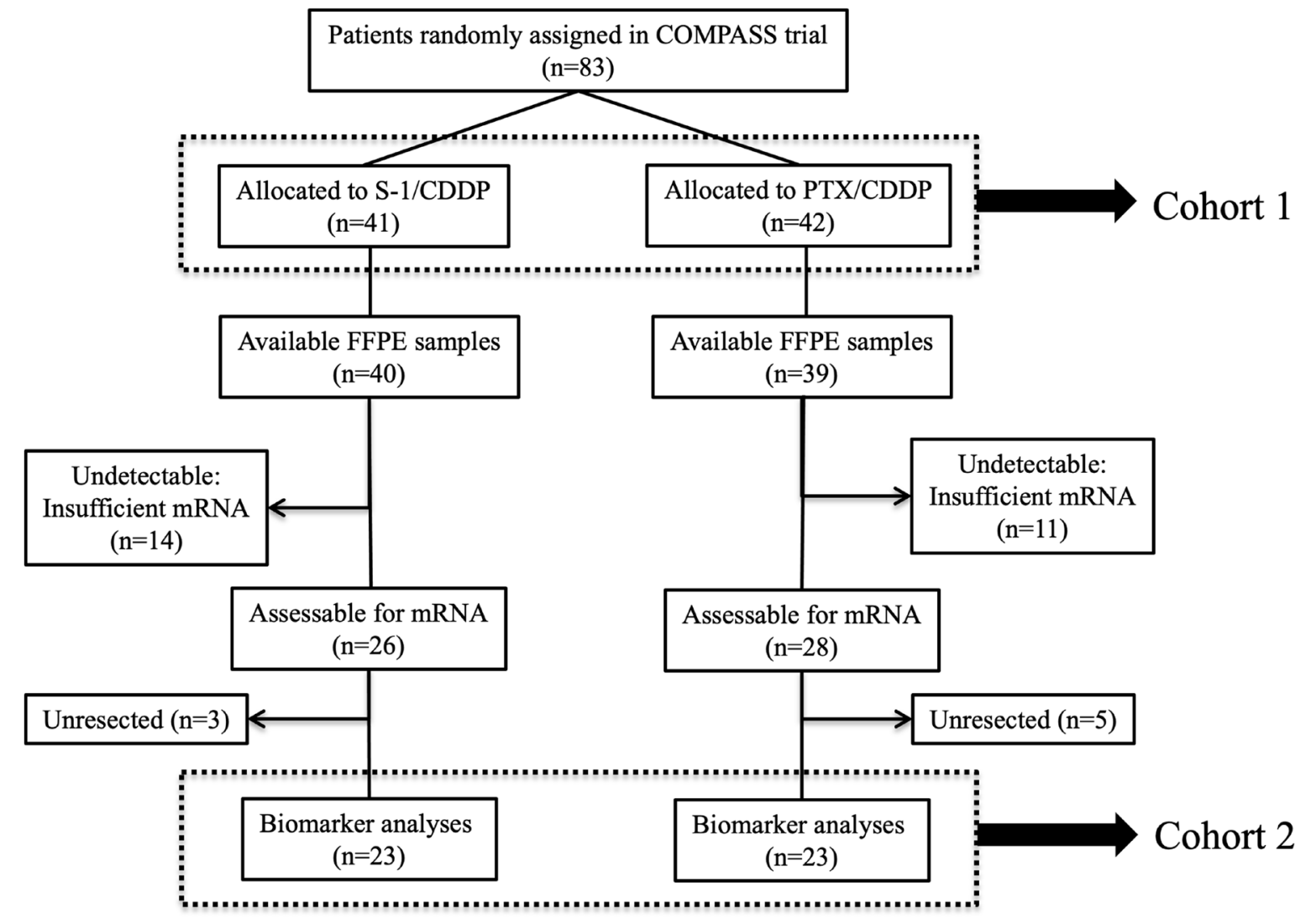

FFPE: formalin-fixed, paraffin-embedded, CDDP: cisplatin, PTX: paclitaxel

Figure 1: CONSORT diagram. Among the 83 patients who participated in the COMPASS trial, mRNA extraction was performed successfully for 78 patients $(94 \%)$ and the expression levels of 127 genes were measurable in 46 patients $(55 \%)$. Twenty-three patients received $\mathrm{SC}$; the remaining 23 received $\mathrm{PC}$. 
Table 1: Patient characteristics

\begin{tabular}{|c|c|c|c|c|c|c|c|c|c|}
\hline \multirow{3}{*}{ Variables/categories } & & \multicolumn{4}{|c|}{ S-1/cisplatin arm } & \multicolumn{4}{|c|}{ Paclitaxel/cisplatin arm } \\
\hline & & \multicolumn{2}{|c|}{ Cohort $1(n=41)$} & \multicolumn{2}{|c|}{ Cohort $2(n=23)$} & \multicolumn{2}{|c|}{ Cohort $1(n=42)$} & \multicolumn{2}{|c|}{ Cohort $2(n=23)$} \\
\hline & & No. & $\%$ & No. & $\%$ & No. & $\%$ & No. & $\%$ \\
\hline Age (years) & Median (range) & \multicolumn{2}{|c|}{$65(32-79)^{*}$} & \multicolumn{2}{|c|}{$66(41-79)^{*}$} & \multicolumn{2}{|c|}{$66(43-80)^{*}$} & \multicolumn{2}{|c|}{$65(44-76)^{*}$} \\
\hline \multirow{2}{*}{ Gender } & Male & 26 & 63 & 15 & 65 & 32 & 76 & 19 & 83 \\
\hline & Female & 15 & 37 & 8 & 35 & 10 & 24 & 4 & 17 \\
\hline \multirow{2}{*}{ Performance status } & 0 & 41 & 100 & 23 & 100 & 40 & 95 & 23 & 100 \\
\hline & 1 & 0 & 0 & 0 & 0 & 2 & 5 & 0 & 0 \\
\hline \multirow{2}{*}{ Macroscopic type } & Non-scirrhous & 30 & 73 & 14 & 61 & 27 & 64 & 14 & 61 \\
\hline & Type 4/giant type 3 & 11 & 27 & 9 & 39 & 15 & 36 & 9 & 39 \\
\hline \multirow{2}{*}{ Histological type } & Differentiated & 17 & 41 & 7 & 30 & 19 & 45 & 11 & 48 \\
\hline & Undifferentiated & 24 & 59 & 16 & 70 & 23 & 55 & 12 & 52 \\
\hline \multirow{4}{*}{ Clinical T } & $\mathrm{T} 2$ & 0 & 0 & 0 & 0 & 1 & 2 & 0 & 0 \\
\hline & $\mathrm{T} 3$ & 2 & 5 & 1 & 4 & 4 & 10 & 1 & 4 \\
\hline & $\mathrm{T} 4 \mathrm{a}$ & 36 & 88 & 20 & 87 & 32 & 76 & 21 & 91 \\
\hline & $\mathrm{T} 4 \mathrm{~b}$ & 3 & 7 & 2 & 9 & 5 & 12 & 1 & 4 \\
\hline \multirow{4}{*}{ Clinical N } & No & 5 & 12 & 4 & 17 & 7 & 17 & 5 & 22 \\
\hline & N1 & 19 & 46 & 11 & 48 & 16 & 38 & 8 & 35 \\
\hline & $\mathrm{N} 2$ & 17 & 41 & 8 & 35 & 18 & 43 & 9 & 39 \\
\hline & $\mathrm{N} 3$ & 0 & 0 & 0 & 0 & 1 & 2 & 1 & 4 \\
\hline \multirow{2}{*}{ Clinical M } & Negative & 35 & 85 & 21 & 91 & 34 & 81 & 21 & 91 \\
\hline & Positive & 6 & 15 & 2 & 9 & 8 & 19 & 2 & 9 \\
\hline \multirow{2}{*}{ Site of M } & $\mathrm{CY} 1^{* *}$ and $\mathrm{P}^{* * * *}$ & 6 & 100 & 2 & 100 & 7 & 88 & 2 & 100 \\
\hline & Para-aortic nodes & 0 & 0 & 0 & 0 & 1 & 12 & 0 & 0 \\
\hline
\end{tabular}

"Expressed as median (range), ${ }^{* *} \mathrm{CY} 1$; positive for peritoneal lavage cytology, ${ }^{* * * *} \mathrm{P} 0$; negative for peritoneal dissemination.

the same samples. Comparison of the mRNA expression levels of samples with high and low immunostaining revealed significant differences between the levels of TIMP1, CLDN18.2, and DSG2 (Figure 3).

In addition, for the expression levels of TIMP1 and $D S G 2$, the concordance rates between the mRNA expression levels that were divided into two by the cutoff value and the protein expression levels determined by immunohistochemical analysis were more than $70 \%$. (Table 4). A retrospective study revealed that the pathological response rate of selecting PC when TIMP1 immunostaining was high and selecting SC when TIMP1 immunostaining was low/negative was $80.0 \%$, and the pathological response rate of selecting SC when DSG2 immunostaining was high and selecting PC when DSG2 immunostaining was low was $88.9 \%$ (Table 5).

Based on these results, TIMP1 and DSG2 were identified as the biomarkers that could possibly predict the pathological response of locally advanced GC to each NAC regimen.

\section{DISCUSSION}

To the best of our knowledge, this is the first study to investigate biomarkers predicting the pathological response to NAC regimens in advanced GC. The findings of the randomized phase II NAC study (COMPASS) suggested that the selection of the NAC regimen and courses did not impact the pathological response. However, it was noteworthy that a pathological complete response was achieved in $10 \%$ of the patients who received four courses of either SC or PC. This result suggested that there may be optimal NAC regimens for the treatment of various tumors. Therefore, we hypothesized that if the types of tumors that are likely to elicit a remarkable pathological response to NAC could be identified prior to treatment initiation, further improvements in outcomes could be expected. This study primarily aimed to determine the feasibility of personalizing a NAC regimen to treat locally advanced GC using regimen selection biomarkers.

In this biomarker study, which included the findings of the COMPASS phase II trial [12], the association between the expression levels of 127 preselected genes in the endoscopic biopsy specimens collected before NAC and the pathological response to the $\mathrm{SC}$ or $\mathrm{PC}$ regimens of NAC were analyzed in patients with locally advanced GC. Based on the mRNA expression levels, TIMP1, DSG2, RRM1, MUC2, EGFR, ZDHHC14, and CLDN18.2 were denoted as the potential biomarker candidates that could predict the pathological response of locally advanced GC to each NAC regimen. The examination of the relationship between the expression of the biomarker genes and proteins 
Table 2: Pathological response in primary tumors based on criteria proposed by the MD Anderson Cancer Center

\begin{tabular}{|c|c|c|c|c|c|c|c|c|}
\hline \multirow{3}{*}{$\begin{array}{l}\text { Pathological response } \\
\text { (grade) }\end{array}$} & \multicolumn{4}{|c|}{ S-1/cisplatin arm } & \multicolumn{4}{|c|}{ Paclitaxel/cisplatin arm } \\
\hline & \multicolumn{2}{|c|}{ Cohort $1(n=41)$} & \multicolumn{2}{|c|}{ Cohort $2(n=23)$} & \multicolumn{2}{|c|}{ Cohort $1(n=42)$} & \multicolumn{2}{|c|}{ Cohort $2(n=23)$} \\
\hline & No. & $\%$ & No. & $\%$ & No. & $\%$ & No. & $\%$ \\
\hline $\mathrm{I}$ & 6 & 15 & 3 & 13 & 4 & 10 & 1 & 4 \\
\hline IIa & 15 & 37 & 8 & 35 & 19 & 45 & 9 & 39 \\
\hline $\mathrm{IIb}$ & 11 & 27 & 9 & 39 & 12 & 30 & 11 & 48 \\
\hline III & 4 & 10 & 1 & 4 & 0 & 0 & 0 & 0 \\
\hline IV & 2 & 5 & 2 & 9 & 2 & 5 & 2 & 9 \\
\hline Unknown & 0 & 0 & 0 & 0 & 0 & 0 & 0 & 0 \\
\hline Unresected & 3 & 7 & - & - & 5 & 12 & - & - \\
\hline IIb-IV & $17 / 41$ & $41 \%$ & $12 / 23$ & $52 \%$ & $14 / 42$ & $33 \%$ & $13 / 23$ & $57 \%$ \\
\hline
\end{tabular}

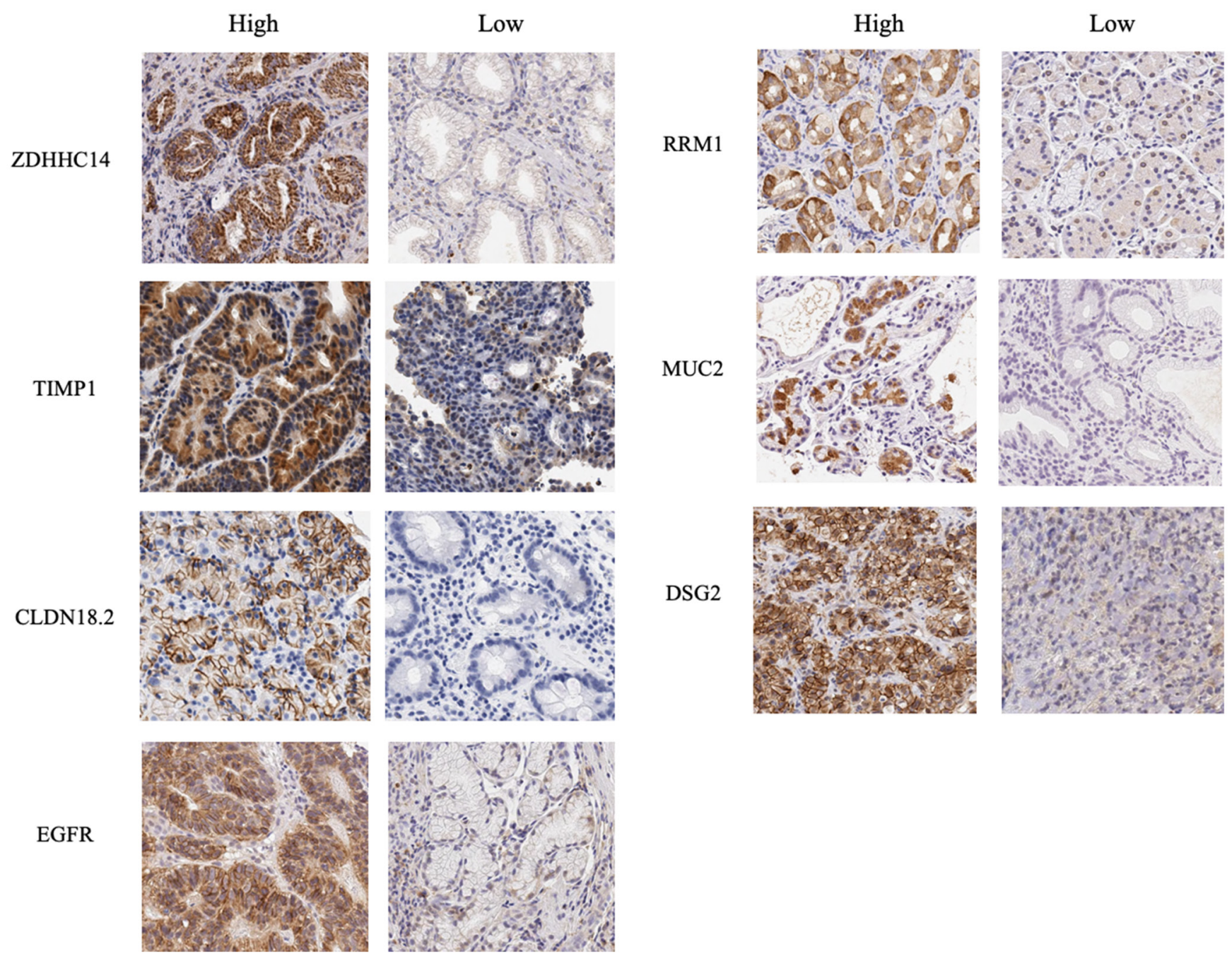

Figure 2: Immunohistochemical images for proteins encoded by seven biomarker candidate genes. Immunohistochemical studies were performed for proteins encoded by seven biomarker candidate genes, ZDHHC14, TIMP1, CLDN18.2, EGFR, RRM1, MUC2 and DSG2 using formalin-fixed, paraffin-embedded biopsy specimens obtained from 24 patients. Immunohistochemical evaluation was performed based on the positive immunostained tumor cells with maximum intensity and the percentage of positive immunostained tumor cells. Representative images of high and low immunostaining of each biomarker candidate are shown. 
Table 3: Biomarker candidates for predicting the pathological response to NAC with SC or PC

\begin{tabular}{|c|c|c|c|c|c|c|c|c|c|}
\hline \multirow{3}{*}{ Biomarker } & \multirow{3}{*}{ Category } & \multicolumn{3}{|c|}{ SC arm } & \multicolumn{3}{|c|}{$\mathrm{PC}$ arm } & \multirow{3}{*}{$\begin{array}{c}\begin{array}{c}\text { Comparison } \\
\text { between the } \\
\text { treatment groups }\end{array} \\
P \text {-value }\end{array}$} & \multirow{3}{*}{$\begin{array}{l}P \text {-value for } \\
\text { treatment } \\
\text { interaction }\end{array}$} \\
\hline & & \multirow{2}{*}{ No. } & \multicolumn{2}{|c|}{ Responders } & \multirow{2}{*}{ No. } & \multicolumn{2}{|c|}{ Responders } & & \\
\hline & & & No. & $\%$ & & No. & $\%$ & & \\
\hline \multirow{2}{*}{ ZDННС14 } & $<0.608$ & 8 & 7 & 87.5 & 7 & 1 & 14.3 & 0.0101 & \multirow{2}{*}{0.0002} \\
\hline & $\geqq 0.608$ & 15 & 5 & 33.3 & 16 & 12 & 75.0 & 0.0319 & \\
\hline \multirow{2}{*}{ TIMP1 } & $<10.473$ & 18 & 7 & 38.9 & 20 & 13 & 65.0 & 0.1927 & \multirow{2}{*}{0.0013} \\
\hline & $\geqq 10.473$ & 5 & 5 & 100 & 3 & 0 & 0.0 & 0.0179 & \\
\hline \multirow{2}{*}{ CLDN18.2 } & $<23.564$ & 11 & 8 & 72.7 & 17 & 7 & 41.2 & 0.1367 & \multirow{2}{*}{0.0016} \\
\hline & $\geqq 23.564$ & 12 & 4 & 33.3 & 6 & 6 & 100 & 0.0128 & \\
\hline \multirow{2}{*}{$E G F R$} & $<0.549$ & 13 & 9 & 69.2 & 12 & 4 & 33.3 & 0.1152 & \multirow{2}{*}{0.0028} \\
\hline & $\geqq 0.549$ & 10 & 3 & 30.0 & 11 & 9 & 81.8 & 0.0299 & \\
\hline \multirow{2}{*}{$R R M 1$} & $<0.803$ & 15 & 7 & 46.7 & 18 & 13 & 72.2 & 0.1686 & \multirow{2}{*}{0.0075} \\
\hline & $\geqq 0.803$ & 8 & 5 & 62.5 & 5 & 0 & 0.0 & 0.0754 & \\
\hline \multirow{2}{*}{$M U C 2$} & $<14.04$ & 18 & 7 & 38.9 & 19 & 12 & 63.2 & 0.1939 & \multirow{2}{*}{0.0077} \\
\hline & $\geqq 14.04$ & 5 & 5 & 100 & 4 & 1 & 25.0 & 0.0476 & \\
\hline \multirow{2}{*}{ DSG2 } & $<4.312$ & 10 & 3 & 30.0 & 12 & 9 & 75.0 & 0.0836 & \multirow{2}{*}{0.0091} \\
\hline & $\geqq 4.312$ & 13 & 9 & 69.2 & 11 & 4 & 36.7 & 0.2173 & \\
\hline
\end{tabular}

Abbreviations; SC: S-1/Cisplatin, PC: Paclitaxel/Cisplatin.

using immunohistochemistry suggested that TIMP1 and DSG2 could be effective as predictive biomarkers of the pathological response to each NAC regimen.

TIMP1 is a specific inhibitor of simultaneously expressing matrix metalloproteinase. It controls the matrix metalloproteinase-mediated degradation of extracellular matrix protein, which is an essential step in cancer cell invasion and metastasis. High expression of TIMP1 was observed in GC and has been associated with recurrence and outcomes $[14,15]$. With respect to the relation between TIMPI and chemotherapy, high TIMP1 expression correlated with a positive response to 5 -fluorouracil-based regimens in patients with colorectal cancer $[16,17]$. Moreover, another study reported that elevated tumor tissue TIMP1 levels were significantly associated with a poor response to paclitaxel-based chemotherapy in patients with breast cancer [18].

DSG2 is one of the components of the cell-cell adherence junction. The association of reduced $D S G 2$ expression with diffuse-type $\mathrm{GC}$ and poor prognosis has been reported earlier [19]. Reportedly, the recombinant adenovirus serotype 3-derived protein (JO-1), which triggers the transient opening of intercellular junctions in epithelial tumors by binding to DSG2, enhanced the antitumor activity of several therapeutic monoclonal antibodies in breast cancer, lung cancer, and GC [20]. Moreover, JO-1 enhances the efficacy of 5-fluorouracil and other chemotherapeutic agents and has been shown to play a role in overcoming drug resistance in several models [21].

A retrospective study revealed that the pathological response rate of selecting NAC regimen based on the expression levels of these biomarkers using immunohistochemistry analysis was high. Although the clinical application of this study requires further validation, it may be a first step towards personalized NAC treatment based on biomarkers.

This study has several limitations. First, the sample size was limited; only 46 (55\%) patients were examined in this study, which could have increased the alpha error. For clinical applications, we opine that a validation study in other cohorts with a large sample size and a single blind study are necessary. Second, the tumor heterogeneity poses a challenge. Although biopsy samples for the biomarker analysis were obtained from four to six tumor sites in each patient, it is difficult to evaluate whether the biopsy samples faithfully represented the characteristics of the entire tumor.

In conclusion, the biomarkers predicting the pathological response of locally advanced GC to each NAC regimen were identified. Based on our results, the possibility of personalizing NAC treatment using biomarkers was suggested. Our results might pave the way for clinical trials on biomarker-oriented NAC.

\section{MATERIALS AND METHODS}

\section{The COMPASS study}

The COMPASS study (UMIN-000002595) enrolled patients with clinical stage III GC and with R0 or R1resectable stage IV GC. Thin-slice CT or multi-detector row $\mathrm{CT}$ and diagnostic laparoscopy were mandatory for clinical staging. The $\mathrm{T}$ and $\mathrm{N}$ criteria were determined precisely based on the protocol. Eligible patients were registered and subsequently randomized by centralized dynamic randomization with the following stratification 
Table 4: The relationship between the relative expression of mRNA and proteins in immunohistochemical analysis

\begin{tabular}{|c|c|c|c|c|c|c|c|c|}
\hline \multicolumn{3}{|c|}{ ZDHHC14 } & \multicolumn{3}{|c|}{ TIMP1 } & \multicolumn{3}{|c|}{ CLDN18.2 } \\
\hline & IHC High & IHC Low & & IHC High & IHC Low & & IHC High & IHC Low \\
\hline mRNA High & 5 & 12 & mRNA High & 6 & 3 & mRNA High & 4 & 0 \\
\hline mRNA Low & 3 & 4 & mRNA Low & 4 & 11 & mRNA Low & 10 & 10 \\
\hline \multicolumn{3}{|c|}{ Concordance rate: $37.5 \%$} & \multicolumn{3}{|c|}{ Concordance rate: $\mathbf{7 0 . 8 \%}$} & \multicolumn{3}{|c|}{ Concordance rate: $58.3 \%$} \\
\hline \multicolumn{3}{|c|}{ RRM1 } & \multicolumn{3}{|c|}{ MUC2 } & \multicolumn{3}{|c|}{ DSG2 } \\
\hline & IHC High & IHC Low & & IHC High & IHC Low & & IHC High & IHC Low \\
\hline mRNA High & 3 & 2 & mRNA High & 4 & 3 & mRNA High & 9 & 3 \\
\hline mRNA Low & 7 & 12 & mRNA Low & 9 & 6 & mRNA Low & 4 & 8 \\
\hline \multicolumn{3}{|c|}{ Concordance rate: $62.5 \%$} & \multicolumn{3}{|c|}{ Concordance rate: $41.7 \%$} & \multicolumn{3}{|c|}{ Concordance rate: $\mathbf{7 0 . 8 \%}$} \\
\hline \multicolumn{3}{|c|}{ EGFR } & & & & & & \\
\hline & IHC High & IHC Low & & & & & & \\
\hline mRNA High & 4 & 6 & & & & & & \\
\hline mRNA Low & 2 & 12 & & & & & & \\
\hline \multicolumn{3}{|c|}{ Concordance rate: $66.7 \%$} & & & & & & \\
\hline
\end{tabular}

Abbreviation; IHC: immunohistochemistry.

factors: macroscopic type, esophageal invasion, M1 stage, and creatinine clearance. Patients were randomly assigned to receive NAC with SC or PC. In the SC regimen, S-1 was administered twice daily at a total dose of $80 \mathrm{mg} / \mathrm{m}^{2}$ for the first three weeks of a four-week cycle, and cisplatin was administered as an intravenous infusion of $60 \mathrm{mg} / \mathrm{m}^{2}$ on day 8 of each cycle, as described previously [22]. In the PC regimen, paclitaxel $\left(60 \mathrm{mg} / \mathrm{m}^{2}\right)$ and cisplatin $(25 \mathrm{mg} /$ $\mathrm{m}^{2}$ ) were administered on days 1,8 , and 15 in one course; this was repeated every four weeks. The details of NAC treatments have been reported previously [23]. Patients proceeded to surgery after receiving NAC. Standard D2 gastrectomy was performed with the goal of ensuring an $\mathrm{R} 0$ resection [24].

The pathological response was evaluated according to the MD Anderson Cancer Centre regression grading systems. Surgical specimens were pathologically categorized as "I" when there was less than $10 \%$ or no tumor cell destruction, as "IIa" when there was 10 to $50 \%$ destruction of tumor cells, as "IIb" when there was 51 to $90 \%$ destruction of tumor cells, "III" when there were viable tumor cells, and "IV" when there was no viable residual tumor (complete response). The pathological responders were patients with tumors eliciting a IIb-, III-, or IV-type response. The protocol of this biomarker study was approved by the institutional review board/ethics committee of each participating institution.

\section{RNA extraction and complementary DNA (cDNA) synthesis}

The present study involved the retrospective collection of formalin-fixed, paraffin-embedded GC tissue specimens that had been obtained endoscopically prior to NAC. The tissue specimens were thinly sliced (thickness, $10 \mu \mathrm{m}$ ); five slices were mounted on glass slides. The cancer site was manually dissected and the sample was transferred to a micro-tube. Total RNA was isolated from GC tissues using NucleoSpin ${ }^{\circledR}$ FFPE RNA XS (MACHEREY-NAGEL GmbH \& Co. KG, Düren, Germany). We performed the quality control of RNA under careful observation. We measured $\mathrm{OD}_{260} / \mathrm{OD}_{280}$ to assess the purity of total RNA using a microvolume spectrometer, NanoDrop 2000, (Thermo Fisher Scientific Inc., MA, USA), and measured the total RNA Integrity Number to assess the fragmentation of RNA using an Agilent 2100 Bioanalyzer (Agilent Technologies Inc., Waldbronn, Germany). We prepared cDNA only from samples that met these quality control criteria for RNA. cDNA was synthesized from $0.4 \mu \mathrm{g}$ of total RNA using an iScript cDNA Synthesis Kit (Bio-Rad Laboratories Ltd., CA, USA). After synthesis, the cDNA was diluted to 0.2 $\mu \mathrm{g} / \mu \mathrm{l}$ with water and stored at $-20^{\circ} \mathrm{C}$ until use.

\section{Quantitative real-time polymerase chain reaction (PCR)}

Quantitative real-time PCR was performed using the iQ SYBR Green Supermix (Bio-Rad Laboratories Ltd, CA, USA). PCR reactions were conducted in a total volume of $15 \mu \mathrm{l}$, which included $0.2 \mu \mathrm{g}$ of cDNA, $0.4 \mu \mathrm{M}$ of each primer, $7.5 \mu \mathrm{l}$ of the iQ SYBR Green Supermix containing dATP, dCTP, dGTP, and dTTP at $400 \mu \mathrm{M}$ each, and 50 units $/ \mathrm{ml}$ of iTag DNA polymerase. The PCR cycle proceeded as follows: $10 \mathrm{~min}$ at $95^{\circ} \mathrm{C}$, followed by 40 cycles of denaturation of the cDNA for $10 \mathrm{~s}$ at $95^{\circ} \mathrm{C}$, annealing for $10 \mathrm{~s}$ at a temperature suitable for each gene, and primer extension for $20 \mathrm{~s}$ at $72^{\circ} \mathrm{C}$, followed by holding for $10 \mathrm{~min}$ at $72^{\circ} \mathrm{C}$. Melting curve analyses were performed to distinguish specific and nonspecific products and the primer dimers. The quantification of each gene was performed in triplicate. A standard curve was 
A

Protein expression in immunohistochemical analysis

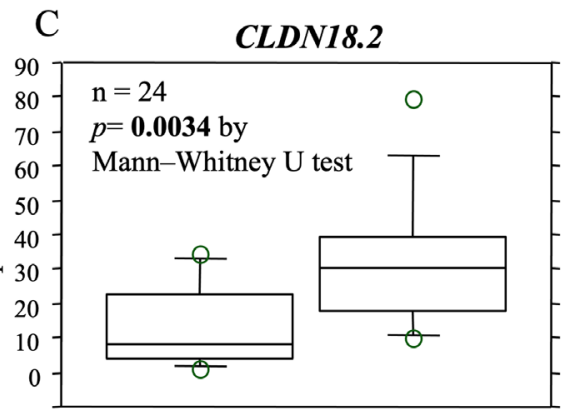

Low

High

Protein expression in immunohistochemical analysis

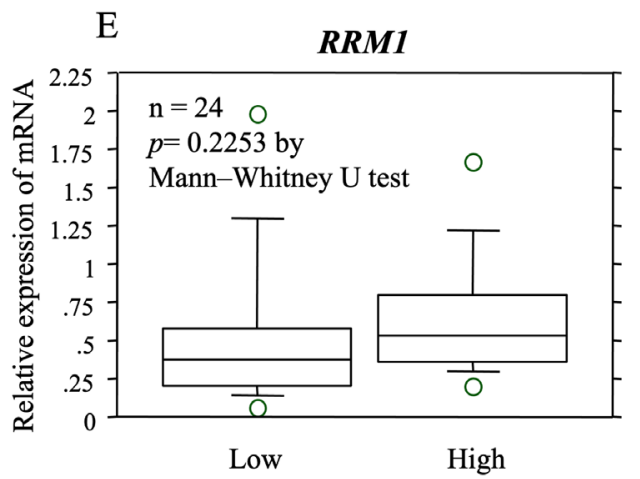

Protein expression in immunohistochemical analysis

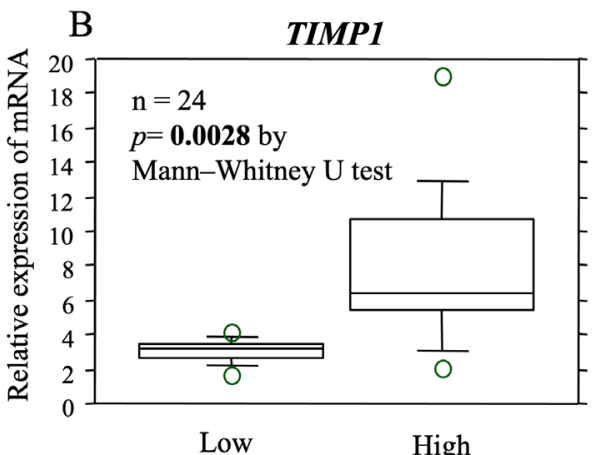

Protein expression in immunohistochemical analysis

$\mathrm{D}$

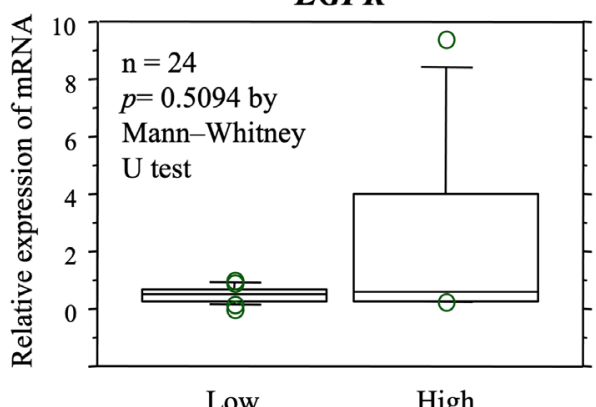

Low

High

Protein expression in immunohistochemical analysis

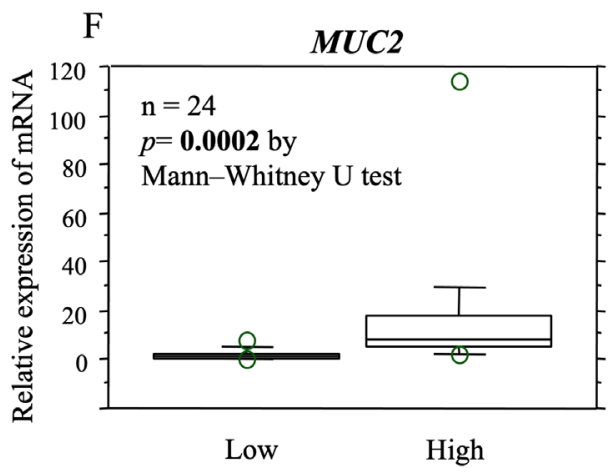

Protein expression in immunohistochemical analysis

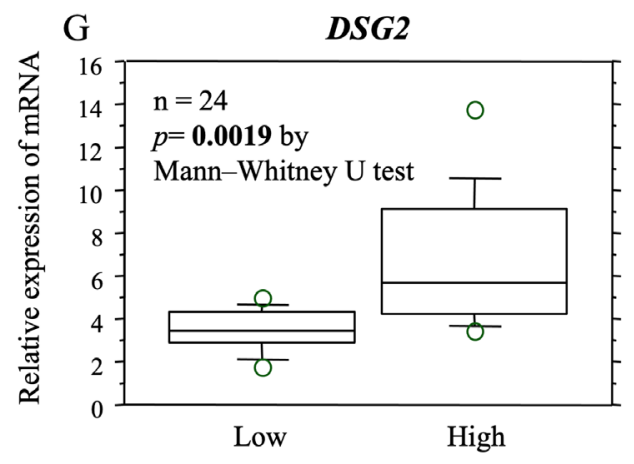

Protein expression in immunohistochemical analysis

Figure 3: The relationship between protein and gene expression determined by immunohistochemical and mRNA expression analysis in the same specimens. The expression of proteins encoded by the biomarker candidates was examined at the mRNA level in the same samples. Based on the comparison of the mRNA expression levels of samples that were high immunoreactivity and low/negative immunoreactivity, significant differences were observed in the mRNA expression levels of TIMP1 (B), CLDN18.2 (C), and DSG2 (G). There was no significant difference in the expression levels of ZDHHC14 (A), EGFR (D), RRM1 (E), MUC2 (F). 
Table 5: Pathological response when regimen is selected based on TIMP1 or DSG2 expression on IHC by retrospective analysis

\begin{tabular}{|c|c|c|c|c|c|c|}
\hline $\begin{array}{l}\text { Sample } \\
\text { No. }\end{array}$ & $\begin{array}{l}\text { NAC regimen } \\
\text { actually } \\
\text { administrated }\end{array}$ & $\begin{array}{l}\text { Regimen selected } \\
\text { based on TIMP1 } \\
\text { expression }\end{array}$ & $\begin{array}{l}\text { Pathological } \\
\text { response }\end{array}$ & $\begin{array}{l}\text { NAC regimen actually } \\
\text { administrated }\end{array}$ & $\begin{array}{l}\text { Regimen selected based } \\
\text { on DSG2 expression }\end{array}$ & $\begin{array}{c}\text { Pathological } \\
\text { response }\end{array}$ \\
\hline 1 & $P C$ & $P C$ & positive & $\mathrm{PC}$ & $\mathrm{SC}$ & \\
\hline 2 & $\mathrm{PC}$ & $\mathrm{SC}$ & & PC & $\mathrm{SC}$ & \\
\hline 3 & $\mathrm{SC}$ & $\mathrm{PC}$ & & $S C$ & $S C$ & positive \\
\hline 4 & $S C$ & $S C$ & negative & $S C$ & $S C$ & negative \\
\hline 5 & $\mathrm{PC}$ & $\mathrm{SC}$ & & $\mathrm{PC}$ & $\mathrm{SC}$ & \\
\hline 6 & $P C$ & $P C$ & positive & $P C$ & $P C$ & positive \\
\hline 7 & $\mathrm{PC}$ & $\mathrm{SC}$ & & PC & $\mathrm{SC}$ & \\
\hline 8 & $\mathrm{SC}$ & $\mathrm{PC}$ & & $\mathrm{SC}$ & PC & \\
\hline 9 & $S C$ & $S C$ & positive & $\mathrm{SC}$ & $\mathrm{PC}$ & \\
\hline 10 & $\mathrm{PC}$ & $\mathrm{SC}$ & & $\mathrm{PC}$ & $\mathrm{SC}$ & \\
\hline 11 & $\mathrm{PC}$ & $\mathrm{SC}$ & & $\mathrm{PC}$ & $\mathrm{SC}$ & \\
\hline 12 & $P C$ & $P C$ & positive & $\mathrm{PC}$ & $\mathrm{SC}$ & \\
\hline 13 & $S C$ & $S C$ & positive & $\mathrm{SC}$ & $\mathrm{PC}$ & \\
\hline 14 & $\mathrm{PC}$ & $\mathrm{SC}$ & & $P C$ & $P C$ & positive \\
\hline 15 & $\mathrm{SC}$ & PC & & $\mathrm{SC}$ & $\mathrm{PC}$ & \\
\hline 16 & $\mathrm{SC}$ & PC & & $\mathrm{SC}$ & PC & \\
\hline 17 & $S C$ & $S C$ & positive & $S C$ & $S C$ & positive \\
\hline 18 & $\mathrm{PC}$ & $\mathrm{SC}$ & & $\mathrm{PC}$ & $\mathrm{SC}$ & \\
\hline 19 & $S C$ & $S C$ & negative & $\mathrm{SC}$ & $\mathrm{PC}$ & \\
\hline 20 & $S C$ & $S C$ & positive & $S C$ & $S C$ & positive \\
\hline 21 & $\mathrm{PC}$ & $\mathrm{SC}$ & & $P C$ & $P C$ & positive \\
\hline 22 & $\mathrm{SC}$ & $\mathrm{PC}$ & & $S C$ & $S C$ & positive \\
\hline 23 & $P C$ & $P C$ & positive & $P C$ & $P C$ & positive \\
\hline 24 & $\mathrm{SC}$ & $\mathrm{PC}$ & & $\mathrm{SC}$ & $\mathrm{PC}$ & \\
\hline & \multicolumn{2}{|c|}{$\begin{array}{l}\text { Pathological response rate when regimen is } \\
\text { selected by TIMP1 expression }\end{array}$} & $80 \%(8 / 10)$ & \multicolumn{2}{|c|}{$\begin{array}{l}\text { Pathological response rate when regimen is selected } \\
\text { by DSG2 expression }\end{array}$} & $88.9 \%(8 / 9)$ \\
\hline
\end{tabular}

Abbreviations; NAC: neoadjuvant chemotherapy, IHC: immunohistochemistry, SC: S-1/cisplatin, PC: paclitaxel/cisplatin.

constructed for each run by measuring the human control cDNA levels (Clontech Laboratories, Inc., CA, USA) at three points to evaluate specific mRNA expression in samples. The concentration in each sample was calculated based on its corresponding point of intersection with the standard curve and was then normalized to that of the reference gene, $\beta$-actin.

\section{Gene selection}

In this study, the expression levels of 127 genes were measured (Table 6). We first selected 74 genes based on findings from DNA microarray experiments. Next, based on the evidence from current literature, the genes were selected from 13 categories related to tumor progression or survival in GC patients, and 53 genes that did not overlap with the above 74 genes were added.

We first performed hematoxylin-eosin staining and CDH17 and LGALS4 immunostaining using 400 frozen specimens excised by surgery for locally advanced GC and selected the specimens that could be clearly categorized as intestinal or diffused based on histopathological characteristics. Among them, we selected the specimens representing pStage IIIC in which NAC was considered to be most appropriate and which had early recurrence despite receiving adjuvant chemotherapy. Next, total RNA was extracted from the cancer tissue and normal gastric mucosa of the specimens, and the ratio of expression of the 28,869 genes in cancer tissue and normal gastric mucosa was calculated using DNA microarray analysis. From the 267 genes that were expressed four times or more than four times the expression ratio in cancer tissues/normal gastric mucosa, we selected 74 genes that have been associated with cancer in relevant literature. In addition, we searched for genes from 13 categories related to tumor progression or survival in patients with GC, based on evidence from current literature. The 13 categories are: genes related to metabolism or activation of anticancer agents, genes related to growth factor and receptor tyrosine kinases, genes related to the $\mathrm{p} 13 \mathrm{~K}-\mathrm{AKT}$, RAS and RAP1 signaling pathways, tumor suppressor genes, genes 
Table 6: Genes investigated (127 genes)

\begin{tabular}{|c|c|c|c|c|c|c|c|}
\hline \multicolumn{8}{|c|}{ 1. Genes related to the metabolism or activation of anticancer agents } \\
\hline$T Y M S$ & $D P Y D$ & $U M P S$ & TK1 & TYMP & $G G H$ & DUT & MTHFR \\
\hline$R R M 1$ & $R R M 2$ & $F P G S$ & DHFR & ERCC1 & TOP $2 A$ & $M A P T$ & TOP1 \\
\hline \multicolumn{8}{|c|}{ 2. Genes related to growth factors and receptor tyrosine kinases } \\
\hline$E G F$ & $A R E G$ & EREG & VEGFA & $I G F 2$ & $H G F$ & MET & FGFR2 \\
\hline$E G F R$ & $E R B B 2$ & $K D R$ & $I G F 1 R$ & PDGFRB & & & \\
\hline \multicolumn{8}{|c|}{ 3. Genes related to the p13K-AKT, RAS, and RAP1 signaling pathways } \\
\hline PTEN & $I T G B 3$ & PLA2G2A & THBS1 & & & & \\
\hline \multicolumn{8}{|c|}{ 4. Tumor suppressor genes } \\
\hline$S E M A 3 B$ & RUNX3 & MLH1 & $A P C$ & DAPK1 & $M G M T$ & $C D K N 2 A$ & \\
\hline \multicolumn{8}{|c|}{ 5. Genes related to apoptosis } \\
\hline$E 2 F 1$ & $B C L 2$ & GADD45 & $F A S$ & BIRC5 & $B C L 2 L 11$ & $B A X$ & $C C N D 1$ \\
\hline \multicolumn{8}{|c|}{ 6. Genes related to cancer stem cells } \\
\hline$\overline{L G R 5}$ & PROM1 & $C D 44$ & NANOG & MSI1 & & & \\
\hline \multicolumn{8}{|c|}{ 7. Genes related to anticancer drug resistance } \\
\hline$A B C G 2$ & $A B C B 1$ & $A B C C 1$ & CAV1 & & & & \\
\hline \multicolumn{8}{|c|}{ 8. Genes encoding members of the MMP family } \\
\hline$M M P 2$ & $M M P 7$ & MMP9 & MMP11 & $M M P 14$ & TIMP1 & & \\
\hline \multicolumn{8}{|c|}{ 9. Genes encoding cell adhesion factors and extracellular matrix } \\
\hline $\mathrm{CDH17}$ & LGALS4 & VCAMI & HPSE & $D S G 2$ & $C D X 2$ & & \\
\hline \multicolumn{8}{|c|}{ 10. Genes of the claudin family } \\
\hline$C L D N 3$ & CLDN4 & CLDN7 & CLDN18.2 & & & & \\
\hline \multicolumn{8}{|c|}{ 11. Genes encoding chemokine receptors } \\
\hline$C C R 7$ & CXCR4 & & & & & & \\
\hline \multicolumn{8}{|c|}{ 12. Epigenetic repression genes } \\
\hline$H D A C 1$ & $E Z H 2$ & & & & & & \\
\hline \multicolumn{8}{|c|}{ 13. Genes identified by SAGE and CAST methods } \\
\hline$A P O E$ & REG4 & MIA & OLFM4 & SEC11A & TSPAN8 & TM9SF3 & ZDHHC14 \\
\hline \multicolumn{8}{|l|}{ CAND1 } \\
\hline \multicolumn{8}{|c|}{ 14. Others } \\
\hline$I N H B A$ & CEMIP & SATB2 & TNS4 & HOXB9 & COL1A2 & $I G F 2 B P 3$ & GDF15 \\
\hline CSAG2 & $\angle A P T M 4 B$ & SLCO1B3 & CEACAM6 & VSNL1 & MUC12 & $S R P X 2$ & SEMA5A \\
\hline TKTL1 & $C C N E 1$ & SLPI & ESM1 & PDCD5 & $S L C 34 A 2$ & SULF1 & CEACAM7 \\
\hline SPARC & PECAM1 & IGFBP3 & ANGPT2 & $M U C 2$ & PPARG & ESR1 & PER2 \\
\hline ARNTL & SIRT1 & GSTO1 & GZMA & LDHA & $P T G S 2$ & $P L A U$ & $T G F A$ \\
\hline
\end{tabular}

related to apoptosis, genes related to cancer stem cells, genes related to anticancer drug resistance, genes encoding members of MMP family, genes encoding cell adhesion factors and extracellular matrix, genes of the claudin family, genes encoding chemokine receptors, epigenetic regression genes, genes identified by serial analysis of gene expression (SAGE) or the Escherichia coli ampicillin secretion trap (CAST) method [25]. The total number of genes included were 127 , except for those that were duplicated.

\section{Immunohistochemical analyses of proteins encoded by the biomarker candidate genes}

Immunohistochemical analyses were performed for EGFR, ZDHHC14, CLDN18.2, TIMP1, DSG2,
MUC2, and RRM1 using formalin-fixed, paraffinembedded biopsy specimens obtained from 24 patients. The tissue sections were deparaffinized and soaked in $10 \mathrm{mM}$ sodium citrate buffer $(\mathrm{pH} 6.0)$ at $121^{\circ} \mathrm{C}$ for 15 min to retrieve the cellular antigens. After blocking, the sections were incubated overnight with the primary antibodies at $4^{\circ} \mathrm{C}$ to allow antigen-antibody reactions to occur. The anti-EGFR antibody (ab52894, Abcam PLC, Cambridge, UK), anti-ZDHHC14 antibody (ab237503, Abcam), anti-CLDN18.2 antibody (ab225512, Abcam), anti-TIMP1 antibody (ab109125, Abcam), anti-DSG2 antibody (ab150372, Abcam), and anti-RRM1 antibody (ab137114, Abcam) were used as primary antibodies. Preliminary examination was performed using positive controls to determine the optimal dilution of each 
antibody and antigen-antibody reactions were performed subsequently. A peroxidase-labeled polymer (EnVision+, rabbit, DAKO, Glostrup, Denmark) was used to detect the signals from the antigen-antibody reactions. All sections were counterstained with hematoxylin. Immunohistochemical evaluation was performed according to a modified immunoreactivity scoring system (IRS): Category A categorized the positive immunostained tumor cells with maximum intensity as absent (0), weak (1), moderate (2), and strong (3). Category $\mathrm{B}$ categorized the percentage of positive immunostained tumor cells into four grades $(0,1,2,3)$ based on the marker-specific approach. The scores from categories A and B added up to an IRS of 0 to 6 . The IRS of 0 to 4 was defined as low/negative immunoreactivity and those of 5 to 6 was defined as high immunoreactivity.

The relationship between protein and gene expression determined by immunohistochemical and mRNA expression analysis in the same specimens was then examined. In addition, the concordance rate between the mRNA expression levels which were divided into two by the cutoff value and the protein expression levels determined by immunohistochemical analysis was examined.

\section{Statistical analysis}

In the identification of biomarker candidates at the mRNA level that predict the pathological response to each NAC regimen, we formed two subgroups by altering the cutoff values of the expression levels of each of the 127 genes and searched for cutoff values that were associated with the interaction having minimum $P$-values between the two subgroups and the pathological response to either SC or PC in each gene using logistic regression analysis. Next, we identified the genes with statistically significant interactions $(P<$ $0.01)$. In our analysis of the relationship between protein and gene expression using immunohistochemical and mRNA expression analyses, respectively, the MannWhitney $U$ test was used for comparing the averages of mRNA expression levels.

\section{Abbreviations}

GC: gastric cancer; NAC: neoadjuvant chemotherapy; SC: S-1/cisplatin; PC: S-1/paclitaxel; OS: overall survival; P0CY1: no peritoneal metastasis and peritoneal lavage cytology positive; JO-1: the recombinant adenovirus serotype 3-derived protein; PCR: polymerase chain reaction; cDNA: complementary DNA.

\section{Author contributions}

Conceptualization and study design were undertaken by T. Oshima and T. Yoshikawa. The tissue specimens were collected by K. Tanabe, K. Nishikawa, Y. Ito, T. Matsui, Y. Kimura, T. Aoyama, T. Hayashi, T. Ogata, H. Cho, and Y. Rino. The experiments were performed by Y. Miyagi, T. Yokose, Y. Hiroshima, and T. Oshima. Statistical analysis and interpretation were performed by S. Morita, M. Yamamoto, and T. Oshima. Interpretation of data was performed by all investigators. The article and figures were drafted by T. Oshima, T. Yoshikawa, S. Morita, and M. Yamamoto. Finally, this article was revised and approved by all investigators, and all authors actively participated in this study.

\section{ACKNOWLEDGMENTS}

We thank Dr. Naoki Hirabayashi (Department of Surgery, Hiroshima City Asa Hospital, Hiroshima, Japan), Dr. Shoki Mikata (Department of Upper Gastrointestinal Surgery, Osaka-Rosai Hospital, Osaka, Japan), Dr. Makoto Iwahashi (Department of Surgery, Wakayama Medical University, Wakayama, Japan), Dr. Ryoji Fukushima (Department of Surgery, Teikyo University, Tokyo, Japan), Dr. Nobuhiro Takiguchi (Department of Gastroenterological Surgery, Chiba Cancer Center, Chiba, Japan), and Dr. Isao Miyashiro (Department of Gastrointestinal Surgery, Osaka Medical Center for Cancer and Cardiovascular Diseases, Osaka, Japan) for their effort in the enrollment of patients, and Ms. Rika Takahashi (Secretary of Department of Gastrointestinal Surgery, Kanagawa Cancer Center, Yokohama, Japan) for her remarkable assistance in data acquisition.

\section{Ethics statement}

All procedures followed were in compliance with the ethical standards of the respective committees on human experimentation (institutional and national) and with the Helsinki Declaration of 1964 and later versions. The protocol used for the current biomarker study was approved by the ethics committee of the Kanagawa Cancer Center and the institutional review board of each participating hospital.

\section{CONFLICTS OF INTEREST}

TO: Research Funding: Taiho pharmaceutical Co., Ltd, Chugai pharmaceutical Co., Ltd, Ono pharmaceutical Co., Ltd, Daiitisankyo pharmaceutical, Nippon Kayaku Co., Ltd, and Eli Lilly Japan K. K. Lecture fees: Nippon Kayaku Co., Ltd, Ono pharmaceutical Co.Ltd and Bristol-Myers Squibb K. K. Speaker Bureau: Taiho pharmaceutical Co., Ltd, Chugai pharmaceutical Co., Ltd, Ono pharmaceutical Co., Ltd, Bristol-Myers Squibb K. $\mathrm{K}$ and Eli Lilly Japan K. K. These are unrelated to the submitted work.

TY: Lecture fees from: MSD, ONO, BMS, Taiho, Chugai, Daiichi-Sankyo, Lilly, Johnson and Johnson, 
Covidien, and Olympus. Personal grant from Lilly. These are unrelated to the submitted work.

YM: Lecture fees from AstraZeneca, Taiho, Chugai, and Daiichi-Sankyo. Consigned research fund from Toso company, Limited, Japan. These are unrelated to the submitted work.

YR: Speaker Bureau from; Daiichi-Sankyo, Johnson and Johnson, Otsuka, Lilly, Taiho pharmaceutical, BristolMyers Squibb. Research Funding: Taiho pharmaceutical, Abbott, Asahi Kasei, Daiichi-Sankyo, Tsumura \& Co., Covidien, Zeria pharmaceutical, Otsuka, EA Pharma, Johnson and Johnson. These are unrelated to the submitted work.

MM: Research Funding from Chugai pharmaceutical, Teijin pharmaceutical, Daiitisankyo pharmaceutical, Takeda pharmaceutical, Terumo Co.Ltd., Japan Lifeline Co.Ltd, Senko Co.Ltd. These are unrelated to the submitted work.

The other co-authors declare no conflicts of interest relevant to this work.

KY: Speaker Bureau from; Bristol-Myers Squibb K. K., Chugai pharmaceutical, EA Pharma, Eli Lilly Japan K. K., Ono pharmaceutical Co., Ltd, Taiho pharmaceutical Co. and Yakult. These are unrelated to the submitted work.

\section{FUNDING}

This study was supported by two non-governmental organizations: the Epidemiological \& Clinical Research Information Network (ECRIN) and the Kanagawa Standard Anti-Cancer Therapy Support System (KSATSS).

\section{REFERENCES}

1. Bray F, Ferlay J, Soerjomataram I, Siegel RL, Torre LA, Jemal A. Global cancer statistics 2018: GLOBOCAN estimates of incidence and mortality worldwide for 36 cancers in 185 countries. CA Cancer J Clin. 2018; 68:394424. https://doi.org/10.3322/caac.21492. [PubMed]

2. Sakuramoto S, Sasako M, Yamaguchi T, Kinoshita T, Fujii M, Nashimoto A, Furukawa H, Nakajima T, Ohashi Y, Imamura H, Higashino M, Yamamura Y, Kurita A, et al; ACTS-GC Group. Adjuvant chemotherapy for gastric cancer with S-1, an oral fluoropyrimidine. N Engl J Med. 2007; 357:1810-1820. https://doi.org/10.1056/ NEJMoa072252. [PubMed]

3. Bang YJ, Kim YW, Yang HK, Chung HC, Park YK, Lee KH, Lee KW, Kim YH, Noh SI, Cho JY, Mok YJ, Kim $\mathrm{YH}$, Ji J, et al. CLASSIC trial investigators. Adjuvant capecitabine and oxaliplatin for gastric cancer after D2 gastrectomy (CLASSIC): a phase 3 open-label, randomized controlled trial. Lancet. 2012; 379:315-321. https://doi. org/10.1016/S0140-6736(11)61873-4. [PubMed]

4. Yoshida K, Kodera Y, Kochi M, Ichikawa W, Kakeji Y, Sano T, Nagao N, Takahashi M, Takagane A, Watanabe T, Kaji
M, Okitsu H, Nomura T, et al. Addition of Docetaxel to Oral Fluoropyrimidine Improves Efficacy in Patients With Stage III Gastric Cancer: Interim Analysis of JACCRO GC-07, a Randomized Controlled Trial. J Clin Oncol. 2019; 37:12961304. https://doi.org/10.1200/JCO.18.01138. [PubMed]

5. Cunningham D, Allum WH, Stenning SP, Thompson JN, Van de Velde CJ, Nicolson M, Scarffe JH, Lofts FJ, Falk SJ, Iveson TJ, Smith DB, Langley RE, Verma M, et al; MAGIC Trial Participants. Perioperative chemotherapy versus surgery alone for resectable gastroesophageal cancer. N Engl J Med. 2006; 355:11-20. https://doi.org/10.1056/ NEJMoa055531. [PubMed]

6. Macdonald JS, Smalley SR, Benedetti J, Hundahl SA, Estes NC, Stemmermann GN, Haller DG, Ajani JA, Gunderson LL, Jessup JM, Martenson JA. Chemoradiotherapy after surgery compared with surgery alone for adenocarcinoma of the stomach or gastroesophageal junction. N Engl J Med. 2001; 345:725-730. https://doi.org/10.1056/ NEJMoa010187. [PubMed]

7. Sasako M, Sakuramoto S, Katai H, Kinoshita T, Furukawa H, Yamaguchi T, Nashimoto A, Fujii M, Nakajima T, Ohashi Y. Five-year outcomes of a randomized phase III trial comparing adjuvant chemotherapy with S-1 versus surgery alone in stage II or III gastric cancer. J Clin Oncol. 2011; 29:4387-4393. https://doi.org/10.1200/JCO.2011.36.5908. [PubMed]

8. Noh SH, Park SR, Yang HK, Chung HC, Chung IJ, Kim SW, Kim HH, Choi JH, Kim HK, Yu W, Lee JI, Shin DB, Ji $\mathrm{J}$, et al; CLASSIC trial investigators. Adjuvant capecitabine plus oxaliplatin for gastric cancer after D2 gastrectomy (CLASSIC): 5-year follow-up of an open-label, randomized phase 3 trial. Lancet Oncol. 2014; 15:1389-1396. https:// doi.org/10.1016/S1470-2045(14)70473-5. [PubMed]

9. Yoshikawa T, Rino Y, Yukawa N, Oshima T, Tsuburaya A, Masuda M. Neoadjuvant chemotherapy for gastric cancer in Japan: a standing position by comparing with adjuvant chemotherapy. Surg Today. 2014; 44:11-21. https://doi. org/10.1007/s00595-013-0529-1. [PubMed]

10. Terashima M, Iwasaki Y, Mizusawa J, Katayama H, Nakamura K, Katai H, Yoshikawa T, Ito Y, Kaji M, Kimura Y, Hirao M, Yamada M, Kurita A, et al; Stomach Cancer Study Group, Japan Clinical Oncology Group. Randomized phase III trial of gastrectomy with or without neoadjuvant S-1 plus cisplatin for type 4 or large type 3 gastric cancer, the short-term safety and surgical results: Japan Clinical Oncology Group Study (JCOG0501). Gastric Cancer. 2019; 22:1044-1052. https://doi.org/10.1007/s10120-01900941-Z. [PubMed]

11. Kang YK, Yook JH, Park YK, Kim YW, Kim J, Ryu MH, Rha SY, Chung I, Kim I, Oh SC, Yoo C, Choi J, Zang DY, et al. Phase III randomized study of neoadjuvant chemotherapy (CT) with docetaxel(D), oxaliplatin(O) and S-1(S) (DOS) followed by surgery and adjuvant S-1, vs surgery and adjuvant $\mathrm{S}-1$, for resectable advanced gastric cancer (GC) (PRODIGY). Ann Oncol. 2019; 30:v851v934. https://doi.org/10.1093/annonc/mdz394.032. 
12. Yoshikawa T, Tanabe K, Nishikawa K, Ito Y, Matsui T, Kimura Y, Hirabayashi N, Mikata S, Iwahashi M, Fukushima R, Takiguchi N, Miyashiro I, Morita S, et al. Induction of a pathological complete response by four courses of neoadjuvant chemotherapy for gastric cancer: early results of the randomized phase II COMPASS trial. Ann Surg Oncol. 2014; 21:213-219. https://doi. org/10.1245/s10434-013-3055-X. [PubMed]

13. Kodera Y, Ito S, Mochizuki Y, Ohashi N, Tanaka C, Kobayashi D, Kojima H, Matsui T, Kondo K, Fujiwara M. Long-term follow up of patients who were positive for peritoneal lavage cytology: final report from the CCOG0301 study. Gastric Cancer. 2012; 15:335-337. https://doi.org/10.1007/s10120-012-0156-3. [PubMed]

14. Yoshikawa T, Tsuburaya A, Kobayashi O, Sairenji M, Miyagi Y. Protein levels of tissue inhibitor of metalloproteinase-1 in tumor extracts as a marker for prognosis and recurrence in patients with gastric cancer. Gastric Cancer. 2006; 9:106-113. https://doi.org/10.1007/ s10120-006-0362-y. [PubMed]

15. Yoshikawa T, Cho H, Tsuburaya A, Kobayashi O. Impact of plasma tissue inhibitor of MMP-1 on long term survival in patients with gastric cancer. Gastric Cancer. 2009; 12:3136. https://doi.org/10.1007/s10120-008-0494-3. [PubMed]

16. Sørensen NM, Byström P, Christensen IJ, Berglund A, Nielsen HJ, Brünner N, Glimelius B. TIMP-1 is significantly associated with objective response and survival in metastatic colorectal cancer patients receiving combination of irinotecan, 5-fluorouracil, and folinic acid. Clin Cancer Res. 2007; 13:4117-4122. https://doi. org/10.1158/1078-0432.CCR-07-0186. [PubMed]

17. Frederiksen C, Qvortrup C, Christensen IJ, Glimelius B, Berglund A, Jensen BV, Nielsen SE, Keldsen N, Nielsen HJ, Brünner N, Pfeiffer P. Plasma TIMP-1 levels and treatment outcome in patients treated with XELOX for metastatic colorectal cancer. Ann Oncol. 2011; 22:369-375. https:// doi.org/10.1093/annonc/mdq354. [PubMed]

18. Zhu D, Zha X, Hu M, Tao A, Zhou H, Zhou X, Sun Y. High expression of TIMP-1 in human breast cancer tissues is a predictive of resistance to paclitaxel-based chemotherapy. Med Oncol. 2012; 29:3207-3215. https://doi.org/10.1007/ s12032-012-0239-3. [PubMed]
19. Yashiro M, Nishioka N, Hirakawa K. Decreased expression of the adhesion molecule desmoglein-2 is associated with diffuse-type gastric carcinoma. Eur J Cancer. 2006; 42:2397-2403. https://doi.org/10.1016/j.ejca.2006.03.024. [PubMed]

20. Beyer I, van Rensburg R, Strauss R, Li Z, Wang H, Persson J, Song H, Bartek J, Fender P, Lieber A. Epithelial junction opener JO-1 improves monoclonal antibody therapy of cancer. Cancer Res. 2011; 71:7080-7090. https://doi. org/10.1158/0008-5472.CAN-11-2009. [PubMed]

21. Beyer I, Cao H, Persson J, Song H, Richter M, Feng Q, Yumul R, van Rensburg R, Li Z, Berenson R, Carter D, Roffler S, Drescher C, et al. Coadministration of epithelial junction opener JO-1 improves the efficacy and safety of chemotherapeutic drugs. Clin Cancer Res. 2012; 18:33403351. https://doi.org/10.1158/1078-0432.CCR-11-3213. [PubMed]

22. Koizumi W, Narahara H, Hara T, Takagane A, Akiya T, Takagi M, Miyashita K, Nishizaki T, Kobayashi O, Takiyama W, Toh Y, Nagaie T, Takagi S, et al. S-1 plus cisplatin versus S-1 alone for first-line treatment of advanced gastric cancer (SPIRITS trial): a phase III trial. Lancet Oncol. 2008; 9:215-221. https://doi.org/10.1016/ S1470-2045(08)70035-4. [PubMed]

23. Nagata N, Kimura M, Hirabayashi N, Tuburaya A, Murata T, Kondo K, Fukuda Y, Kobayashi M, Miyashita Y, Nakao A, Sakamoto J. Phase II study of weekly paclitaxel and cisplatin combination therapy for advanced or recurrent gastric cancer. Hepatogastroenterology. 2008; 55:18461850. [PubMed]

24. Japanese Gastric Cancer Association. Japanese gastric cancer treatment guidelines 2014 (ver. 4). Gastric Cancer. 2017; 20:1-19. https://doi.org/10.1007/s10120-016-0622-4. [PubMed]

25. Oue N, Sentani K, Sakamoto N, Yasui W. Clinicopathologic and molecular characteristics of gastric cancer showing gastric and intestinal mucin phenotype. Cancer Sci. 2015; 106:951-958. https://doi.org/10.1111/cas.12706. [PubMed] 